Published in final edited form as:

J Pers. 2007 December ; 75(6): 1255-1283.

\title{
Contextualized Self-Representations in Adulthood
}

\author{
Manfred DiehI ${ }^{1}$ and Elizabeth L. Hay ${ }^{2}$ \\ 1 Colorado State University \\ 2University of Florida
}

\section{Abstract}

Theorizing has focused on individuals' self-representations as a psychological resource for coping with life stress and developmental challenges in adulthood. Many of the prominent theories have conceptualized self-representations with regard to specific social contexts (e.g., role-specific selfrepresentations) and have examined specific structural organizations of the self-concept with regard to psychological adjustment. This article describes research on the associations between self-concept structures and psychological well-being in adulthood. Specific emphasis is given to the feature of self-concept differentiation (SCD). Most research suggests that a high level of SCD tends to indicate self-fragmentation and tends to be associated with poorer adjustment and psychological well-being. Findings from a daily diary study with adults of all ages are reported showing that different levels of SCD were in a consistent and meaningful way related to the daily endorsement of positive and negative self-attributes. Daily self-representations, in turn, were significantly related to individuals' level of daily negative affect and to intra-individual variation in negative affect. These findings suggest that SCD may exert its effect on adjustment and psychological well-being through specific ways of processing self-related information.

The last two decades have seen important extensions of self-concept theory into research on adult development and aging (Brandtstädter \& Greve, 1994; Filipp \& Klauer, 1986; Markus $\&$ Herzog, 1991). In particular, theorists have focused on individuals' self-representations as a psychological resource for coping with the challenges of adulthood and old age (Brandtstädter $\&$ Greve, 1994; Freund \& Smith, 1999; Greve \& Wentura, 2003). ${ }^{1}$ Many of these conceptualizations have focused on adults' self-representations with regard to specific social contexts (e.g., role-specific self-representations) and have examined the associations of different structural organizations of contextualized self-representations with different indicators of psychological adjustment (Campbell, Assanand, \& DiPaula, 2003; Kling, Ryff, \& Essex, 1997; Linville, 1987; Showers, Abramson, \& Hogan, 1998).

This article has three major parts. First, we will review the theoretical and empirical reasons that have served as background for studying contextualized self-representations in adulthood. Second, we will review research focusing on the associations between different self-concept organizations and indicators of psychological adjustment. In this review, we will highlight only some of the major findings with regard to certain self-concept organizations and will focus specifically on the associations of self-concept differentiation (SCD) and measures of psychological well-being. Third, we will present findings from cross-sectional studies and from a daily diary study examining the effect of SCD and daily self-representations on daily affect.

Correspondence concerning this article should be addressed to Manfred Diehl, Human Development and Family Studies, Colorado State University, 1570 Campus Delivery, Fort Collins, CO 80523-1570. E-mail: manfred.diehl@ colostate.edu.

${ }^{1}$ We use the terms self-concept and self-representations interchangeably to refer to those attributes or characteristics that are (a) part of a person's self-understanding and self-knowledge, (b) the focus of self-reflection, and (c) consciously acknowledged by the person through language or other means of communication (see Harter, 1999). 


\section{SELF-REPRESENTATIONS: CONTEXTUALIZED AND DYNAMIC}

For the past two decades, theorists and researchers have conceptualized individuals' selfrepresentations as a contextualized and dynamic knowledge structure (i.e., cognitive schema) that serves adaptive and self-regulatory functions (Baumeister, 1998; Higgins, 1996; Markus $\&$ Wurf, 1987). This knowledge structure contains general and context-specific information about traits, beliefs, values, and episodic and semantic memories about the self and is actively involved in the processing of self-relevant information (Campbell et al., 1996). Life span developmental, social, and personality psychologists have embraced this conceptualization for several reasons.

First, for life span developmental and personality psychologists, this conceptualization provides a framework within which both aspects of personality stability (e.g., general selfrepresentations, salient identities) and personality change (e.g., context-specific selfrepresentations) can be addressed in a meaningful way (Caspi \& Roberts, 2001; Mroczek, Spiro, \& Griffin, 2006; Wood \& Roberts, 2006). Moreover, from an adult development perspective, knowledge about the antecedents, correlates, and consequences of generalized and context-specific self-representations is important for optimizing positive developmental outcomes and the process of adult development and aging (Diehl, 2006; Mroczek et al., 2006; Ryff, Kwan, \& Singer, 2001).

Second, conceptualizing and studying adults' self-representations in a contextualized fashion has also redirected the attention of researchers from the content to the structural organization of self-representations (Campbell et al., 2003; Donahue, Robins, Roberts, \& John, 1993; Linville, 1987; Rafaeli-Mor \& Steinberg, 2002; Showers et al., 1998). This redirection has been spearheaded by social and personality psychologists but is also increasingly embraced by life span developmental psychologists (Diehl, Hastings, \& Stanton, 2001; Rothermund \& Meiniger, 2004). The main reason for focusing on the structural organization of individuals' context-specific self-representations is the assumption that different self-structures are associated with different ways of processing self-relevant information, which are, in turn, associated with either adaptive or maladaptive behavior (Campbell et al., 2003; Showers et al., 1998; Showers \& Zeigler-Hill, 2003). Thus, a focus on the structural organization of the selfconcept goes beyond the content of individuals' self-representations and tries to elucidate how organizational features, such as coherence, complexity, or differentiation, may moderate the effects of the self-concept content with regard to psychological outcomes (Diehl et al., 2001; Donahue et al., 1993; Rothermund \& Meiniger, 2004).

Third, the malleable and dynamic nature of adults' self-representations has been mostly examined by social and personality psychologists (Markus \& Wurf, 1987; Showers et al., 1998). For example, laboratory studies have documented that college students respond to different conditions of feedback (e.g., success vs. failure) by dynamically adjusting the content and structure of their self-representations to different situational demands (Markus \& Kunda, 1986). In a more naturalistic setting, and building on findings from earlier research (Linville, 1987; Woolfolk, Novalany, Gara, Allen, \& Polino, 1995), Showers et al. (1998) showed in a prospective study that college students changed their self-concept structure to counteract the effects of stress and negative mood. In combination with research on adults' possible selves (Cross \& Markus, 1991; Hooker, 1999; Smith \& Freund, 2002), these findings suggest that individuals organize and reorganize the structure of their self-knowledge in response to situational or age-related challenges (Greve \& Wentura, 2003). Moreover, this evidence has been complemented by recent findings showing that changes in general trait ratings over a 6month period were predicted by role-specific self-representations, suggesting a bottom-up process at work in personality change (Wood \& Roberts, 2006). 
In summary, conceptualizing self-representations as a contextualized and dynamic cognitive schema represents a major approach to studying an important facet of human personality. In the following, our discussion will focus on research examining the associations between different self-concept organizations and indicators of psychological well-being.

\section{SELF-CONCEPT ORGANIZATION AND PSYCHOLOGICAL WELL-BEING}

The shift in focus from the content to the structural organization of individuals' selfrepresentations has been primarily motivated by the desire to elaborate the processes that underlie the multifaceted and dynamic self-concept (Markus \& Wurf, 1987; Rafaeli-Mor \& Steinberg, 2002). Thus, a growing body of literature has focused on the structural organizations of the self-concept that are involved in the self-regulation of behavior and in processes of adaptation (Rothermund \& Meiniger, 2004; Showers et al., 1998). These organizational structures include, among others, self-concept complexity (Linville, 1987; Margolin \& Niedenthal, 2000; Woolfolk et al., 1995), self-concept compartmentalization (Showers, 1992a, 1992b; Showers et al., 1998), and self-concept differentiation (Diehl et al., 2001; Donahue et al., 1993). Although a detailed review of the literature on each of these organizational structures and their associations with psychological outcomes is beyond the scope of this article, we will briefly highlight some of the most relevant research findings with regard to the effect of self-concept organization on psychological well-being.

\section{Self-Concept Complexity}

Self-concept complexity (Linville, 1985, 1987) is one of the most frequently studied features of self-concept organization and refers to the extent to which a person's different self-aspects are defined by distinct attributes. Thus, measures of self-concept complexity combine two components of a person's self-concept, namely the number of different self-aspects and their distinctness (Rafaeli-Mor \& Steinberg, 2002). A complex individual has many self-aspects that do not overlap in their attribute content.

Linville's (1987) affective spillover hypothesis postulates that greater self-concept complexity should be advantageous in coping with life stress because it results in less spillover from the affected self-aspect to other self-aspects. Although some initial studies provided support for Linville's assumption, the overall empirical findings regarding this hypothesis have been rather mixed (Koch \& Shepperd, 2004; Rafaeli-Mor \& Steinberg, 2002). For example, Rafaeli-Mor and Steinberg's (2002) review of the literature found little support for self-concept complexity as a stress buffer. Instead, these authors showed that self-concept complexity served more often as a moderator of positive, uplifting events. Koch and Shepperd (2004) arrived at similar conclusions. Based on these reviews of the literature, more recent studies have investigated the effects of number of self-aspects and distinctness of self-aspects separately and have shown that it is mostly the number of self-aspects that moderates the relationship between stress and well-being (Rothermund \& Meiniger, 2004).

\section{Self-Concept Compartmentalization}

Self-concept compartmentalization refers to another form of self-concept organization that has been discussed in the social psychological and personality literature. Building on the work of Linville, Showers (1992a) introduced the concept of "self-concept compartmentalization" to refer to a person's tendency to organize his or her self-aspects in such a way that information associated with a given aspect is either uniformly positive or uniformly negative. Individuals who incorporate both positive and negative attributes in their self-aspects are described as having an integrated self-concept organization. 
Although Showers (1992a, 1992b; Showers \& Kling, 1996) has provided considerable empirical evidence in support of her basic model of compartmentalization, findings from more recent studies suggest that simple compartmentalization may only be an easy and effective strategy of first resort when dealing with life stress. In life contexts where stressful situations persist over a longer period of time, integrative organization appears to be the more adaptive self-concept organization. The most convincing evidence in support of this latter argument comes from a prospective longitudinal study showing that integrative self-concept organization was more effective in reducing negative mood when stressors persisted over longer periods of time (Showers et al., 1998).

\section{Self-Concept Differentiation}

Self-concept differentiation (SCD) assesses the degree to which individuals' selfrepresentations are similar or different across different social roles and contexts (Block, 1961; Diehl et al., 2001; Donahue et al., 1993). To assess SCD, individuals usually rate a set of attributes with regard to how characteristic each attribute is separately for a number of social roles or contexts. From these ratings, for each person the degree of nonoverlap among role- or context-specific ratings is calculated as an index of SCD. This measure of self-concept organization has been appealing to developmental and personality psychologists for several reasons.

First, a large body of developmental research has shown that over the course of childhood and adolescence, self-representations develop in a fairly predictable order (Damon \& Hart, 1988; Harter, 1998). An important part of this developmental sequence is the increasing differentiation into role-specific multiple selves by the end of adolescence or beginning of early adulthood (Damon \& Hart, 1988; Harter, 1998; Montemayor \& Eisen, 1977; Rosenberg, 1986). That means, by early adulthood, individuals are confronted with the developmental task of coordinating multiple, role- or context-specific self-representations into a coherent identity - a task that builds on progressions in cognitive and social-emotional development (Harter \& Monsour, 1992). Successful resolution of this developmental task is believed to be an important cornerstone for successful social and emotional development in middle age and later adulthood (Erikson, 1963; Marcia, 1980; Waterman \& Archer, 1990).

Second, personality, social, and clinical psychologists have been interested in SCD because of its relation with adjustment and well-being. On the one hand, some social and personality psychologists have argued that high SCD may be indicative of social specialization (i.e., specialization hypothesis) in response to the demands of different social roles and the rapidly changing demands of postmodern society (Gergen, 1991). Thus, these theorists conceptualize a highly differentiated self-concept as an indication of specialized identities that allow a person to respond flexibly and adaptively to the requirements of different roles and situations (Snyder, 1974). In contrast, other theorists have argued that high SCD may be indicative of fragmentation (i.e., fragmentation hypothesis) and a divided sense of self (Block, 1961; Lecky, 1945; Rogers, 1959). For example, Rogers (1959), in his theory of personality and therapy, elaborated that a coherent and integrated self-concept is a sign of a mentally healthy and welladjusted individual. Similarly, Block (1961) described the person who lacks a coherent core self as an "interpersonal chameleon" (p. 392) who lacks a sense of continuity and may be plagued by a lack of self-integrity.

To date, findings from an increasing number of studies support the fragmentation hypothesis and suggest that high SCD (i.e., low self-concept consistency) is indeed associated with poorer psychological outcomes, such as higher levels of anxiety, depression, and neuroticism and lower levels of self-esteem and indicators of positive psychological well-being (Bigler, Neimeyer, \& Brown, 2001; Donahue et al., 1993; Lutz \& Ross, 2003; McReynolds, Altrocchi, $\&$ House, 2000). However, these studies also have some limitations, especially when the 
associations of SCD with psychological outcomes are approached from a developmental perspective. First, most studies examining the associations of SCD with psychological wellbeing have been conducted with samples of college students and tell us little about possible age differences or age-related changes in SCD across the adult life span (for exceptions, see Diehl et al., 2001; Study 2 in Donahue et al., 1993). Second, recent research has also pointed out that greater clarification about the association of SCD with outcome measures of adjustment and well-being can be achieved by incorporating content aspects (e.g., valence, clarity of the rated self-attributes) of individuals' self-representations. For example, Locke (2006) showed that the associations of SCD with measures of adjustment were different for desirable versus undesirable self-attributes. Third, several authors have also argued that the relations of SCD with measures of adjustment should be evaluated in comparison to other measures of selfstructure, most prominently, self-concept complexity (Campbell et al., 2003; Lutz \& Ross, 2003; Rafaeli-Mor \& Steinberg, 2002). Indeed, researchers who have focused on such a comparison have shown that the associations of SCD with measures of psychological adjustment tend to be different than the associations of self-concept complexity (Campbell et al., 2003; Lutz \& Ross, 2003). Finally, methodological concerns have been raised recently with regard to the operationalization of SCD (Baird, Le, \& Lucas, 2006). Specifically, Baird et al. (2006) have argued that the principal-components-based index that is usually used to assess SCD is less than ideal because it may "confound irrelevant sources of variance with true withinperson variability" (p. 513).

In summary, SCD has been recognized as an important structural feature of the self-concept. In particular, most of the empirical evidence suggests that a highly differentiated self-concept (i.e., a self-concept with low consistency across roles or situations) tends to be indicative of self-fragmentation and tends to be associated with poorer psychological adjustment. However, additional clarifications about the predictive importance of SCD are needed, particularly in light of some recent methodological criticisms (Baird et al., 2006). In the following, we will present findings from a developmentally oriented research program that has examined the role of SCD across the adult life span and has attempted to elucidate the effects of SCD in a number of ways.

\section{SELF-CONCEPT DIFFERENTIATION ACROSS THE ADULT LIFE SPAN}

Studies on the effects of SCD across the adult life span are rare. As already pointed out, most studies by social and personality psychologists have examined SCD in college students (Baird et al., 2006; Block, 1961; Donahue et al., 1993, Study 1; Locke, 2006; Lutz \& Ross, 2003).

Inclusion of adults of all ages, however, is important because during different periods of the adult life span, SCD may have different effects on psychological adjustment. Thus, the following section reviews studies that have addressed the associations of SCD with psychological adjustment and well-being in adult development and aging.

\section{Early Studies on SCD and Adult Development}

The first study that examined the associations of SCD with psychological adjustment in the context of adult development was published by Donahue and her colleagues (1993). These investigators reported findings from the Mills Longitudinal Study of women's development (Helson \& Wink, 1992) showing that SCD assessed when the participants were 52 years old correlated significantly with markers of emotional adjustment at ages 21,27, and 43. Moreover, this study also showed that the strength of the associations between SCD and measures of emotional adjustment and well-being increased across the different ages. Although some of the consecutive increases in the correlation coefficient may be explained by the increasing temporal proximity to the actual assessment of SCD, it is unlikely that all of the observed increase is due to the decreasing time interval. Instead, it seems reasonable to assume that the increases in the strength of the associations reflect a cumulative effect of SCD over time. Hence, 
Donahue et al. (1993) suggested that the negative effects of SCD were more than a transient phenomenon; rather, they reflected "a long-term pattern of both intrapersonal and interpersonal problems" (p. 843). ${ }^{2}$

Donahue et al. (1993) also examined the associations of SCD with social role variables such as self-reported and observer-rated role satisfaction and role changes from age 21 to age 43. These analyses showed that SCD was negatively related to both self-reported and observerrated role satisfaction. Moreover, SCD was positively associated with the number of role changes (e.g., relationship breakups, divorce, job changes, etc.). These findings led Donahue et al. (1993) to the conclusion that "SCD is associated with intrapersonal and interpersonal difficulties marked by emotional distress, rejection of social norms, and volatile role relationships in love and work" (p. 844). These researchers also suggest that these difficulties may reinforce each other and may form a stable pattern that maintains itself over time.

\section{Recent Studies on SCD and Adult Development}

Building on this earlier work, Diehl et al. (2001) investigated SCD from a developmental perspective and examined its age trajectory in a cross-sectional sample, ranging in age from 20 to 88 years. Findings showed that the SCD index had a curvilinear, U-shaped association with participants' age. That is, over the course of young adulthood, the SCD index tended to go down, reaching its lowest level around age 55 . From the late $50 \mathrm{~s}$ to early $60 \mathrm{~s}$ on, it then tended to go up again with age, showing a similarly high level of SCD in the oldest age group as in the youngest age group. Thus, these findings suggested that the level of SCD may be affected by life-stage-specific role demands. For example, in midlife, when adults tend to hold the largest number of social roles and tend to have the heaviest role responsibilities (Lachman, 2004), it may be particularly important to strive for self-concept consistency across roles because inconsistency may put a person at risk for more role-related stress and maladjustment.

Because of the differential relationship with age, Diehl et al. (2001) examined whether age moderated the association of SCD with positive and negative psychological well-being. The findings from these analyses are shown in Figures 1 and 2. As can be seen in Figure 1, the slope of the regression line representing the association between SCD and positive psychological well-being was significantly steeper for older adults than for younger adults. The same pattern is shown in Figure 2 with regard to the association between SCD and negative psychological well-being. In combination, these findings suggested that the negative effect of SCD differed across the adult age groups and was most pronounced in the group of older adults. Or, to say it differently, self-concept coherence played a more important role with regard to psychological well-being in later adulthood than in earlier adulthood. Thus, self-concept coherence may become increasingly important in late life when adults experience losses or are challenged by physical or psychological declines.

Diehl, Hay, and Aertker (2006) also revisited the specialization versus fragmentation hypothesis and examined the joint effect of SCD and self-concept clarity (Campbell et al., 1996) on psychological well-being in two independent studies with adults ranging in age from 18 to 89 years. These studies were motivated by Bigler et al.'s (2001) suggestion that it may

\footnotetext{
${ }^{2}$ Because the standard assessment of SCD requires that individuals rate a list of attributes for different social roles, the question is often raised whether this approach creates specific demand characteristics by inducing participants to indicate different personality characteristics across different roles. This methodological issue was addressed by Donahue et al. (1993). Specifically, these authors assessed SCD under two very different conditions, namely an identity-focused condition (i.e., rating all attributes for one role at a time) and an attribute-focused condition (i.e., rating one attribute for all roles at a time). In the identity-focused condition participants' ratings may be influenced by carry-over effects from one role to the next, whereas in the attribute-focused condition ratings may be influenced by demand effects. The results from this study showed that the measure of SCD was not affected by variations in participants' focus; neither mean scores nor the distributions of the scores differed across conditions. Other controls were implemented in the study by Diehl et al. (2001) showing that the mean level of the SCD index was not affected by the order of administration.
} 
be necessary to examine other structural aspects of individuals' self-representations jointly with SCD in order to test the specialization versus fragmentation hypothesis in a more sensitive way. Specifically, Bigler et al. (2001) proposed that the effects of SCD may be qualified by an individuals' clarity about his or her self-representations (Campbell et al., 1996). For example, it seems plausible that only individuals who have a high level of SCD and great clarity about their self-representations would be expected to support the specialization hypothesis. In contrast, individuals with a high level of SCD and very low clarity would be expected to support the fragmentation hypothesis.

Findings from two independent studies with adults (Study 1: $N=158, M$ age $=50.9$ years, age range $=19-88$ years; Study $2: N=279, M$ age $=48.0$ years, age range $=18-89$ years) provided support for the major hypotheses. In particular, individuals who conformed to the specialization hypothesis (i.e., high SCD and high self-concept clarity) had consistently high scores on measures of positive psychological well-being and consistently low scores on measures of negative psychological well-being. In contrast, individuals who conformed to the fragmentation hypothesis (i.e., high SCD and low self-concept clarity) showed the reversed pattern with measures of psychological well-being. Interestingly, the highest scores on measures of positive psychological well-being and the lowest scores on measures of negative psychological well-being were, however, shown by the group of individuals with low SCDalthough the differences between the specialized group and this group were often not statistically significant.

In summary, findings from these recent age-comparative studies are consistent with the early work by Donahue et al. (1993) and underscore that SCD (i.e., lack of self-coherence) tends to be associated with unfavorable psychological outcomes. However, these studies also show that the negative effect of SCD may vary across the adult life span and that the incorporation of additional structural features of adults' self-representations, such as self-concept clarity, may be useful in elucidating the role of SCD with regard to psychological adjustment and emotional well-being.

A limitation of the presented studies, however, is that they examined the associations of SCD with adults' psychological well-being at a single point in time. To overcome this limitation and to gain a better understanding of the role of self-representations from a more contextualized and dynamic perspective, we conceived a study in which we examined the role of SCD and the valence of daily self-representations with regard to the experience of daily stress, affect, and physical symptoms. The approach taken in this study and select findings are reported next.

\section{SELF-REPRESENTATIONS AND INTRA-INDIVIDUAL VARIABILITY OF BEHAVIOR}

Based on the work of others and the findings from the studies described above, we outlined several propositions that we then tested in a subsequent study. The first proposition stated that the dynamic nature of self-representations is mostly embodied in (a) their structural organization and (b) their situation- or domain-specific valence. The second proposition postulated that the dynamic aspects of self-representations should become most visible in situations in which individuals need to engage in self-regulation of behavior because their psychological or social resources are challenged. Challenges to a person's psychological or social resources tend to occur in the context of stressful situations and, hence, it would be desirable to examine the role of self-representations in the context of individuals' daily stress experiences. Finally, the third proposition stated that aside from conducting long-term longitudinal studies on the developmental change in self-representations, short-term withinperson changes in the structure and valence of self-representations can be productively 
examined in studies with intensive repeated observations, such as experience sampling or daily diary studies.

These propositions provided the background for an empirical study in which we examined the role of adults' self-representations in two major ways. In a first set of analyses, we examined the role of SCD in the context of daily stress and the experience of negative affect. In a second set of analyses, we focused on the assessment of the valence of daily self-representations and examined the associations between the number of positive and the number of negative selfrepresentations and the experience of daily negative affect.

\section{SCD and Intra-Individual Variability in Daily Negative Affect}

Consistent with theorizing about the effects of SCD (Block, 1961; Diehl et al., 2001; Donahue et al., 1993; Lutz \& Ross, 2003), the major assumption that guided this specific research objective was that stressful events create a greater disturbance in the person-environment fit of individuals with higher levels of SCD than in individuals with lower levels of SCD. This assumption was based on the observation that a more incoherent self-concept is more likely to result in greater volatility of behavior (see Donahue et al., 1993) when established routines are challenged by stressful events.

To examine this hypothesis, we conducted a daily diary study with 239 adults (120 men and 119 women) ranging in age from 18 to 89 years ( $M$ age $=49.6$ years, $S D=19.6$ years).

Participants were recruited in north-central Florida using a mix of sampling procedures (i.e., random digit dialing, advertisements). Participants had to be free of major sensory impairment and show no evidence of concurrent depression or history of mental illness. Participants also had to be cognitively and physically able to complete the study protocol. The criteria for study inclusion were established during a screening interview.

To ensure an even distribution of age, participants were recruited in three age groups: young adults ( $n=81$; age range 18-39 years), middle-aged adults ( $n=81$; age range $40-59$ years), and older adults ( $n=77$; age 60 and older). Gender was evenly distributed within each age group.

Eighty-eight percent of the participants were White and could be classified as middle-class socioeconomic status. Most of the young adults were single, whereas most middle-aged and older adults were married. The young adults were approximately evenly divided between those who were employed (full- or part-time) and those who were students, whereas the majority of the middle-aged adults were employed and the majority of the older adults were retired.

Participants described themselves as being in good health and being satisfied with their lives. Additional information with regard to key sociodemographic and health variables are shown in Table 1.

Participants attended an individual baseline session and completed daily assessments for 30 consecutive days. Baseline sessions were conducted by trained research assistants and lasted approximately 2 hours. At baseline, detailed sociodemographic and personal information was collected and participants responded to a number of individual difference measures, including the measures on self-concept differentiation (Block, 1961).

The day following the baseline session, participants began the daily assessments, which consisted of a self-administered diary and a phone interview. Daily phone interviews assessed the stressful events of that day, using the Daily Inventory of Stressful Experiences (DISE; Almeida, Wethington, \& Kessler, 2002). The DISE is a semi-structured interview that was developed on a nationally representative sample of adults; it includes seven stem questions assessing the occurrence of stressors, including having and avoiding arguments, as well as 
stressors that occur in various domains of life (e.g., work/ school/volunteering, family, health, etc.). The interviews were conducted by trained research assistants between $4 \mathrm{pm}$ and $9 \mathrm{pm}$ every day, and every effort was made to interview participants at about the same time each day, keeping the time interval between days as constant as possible.

The daily diaries were self-administered and assessed physical symptoms, positive and negative affect, self-attributes, and mood states the participants' experienced that day. Participants were instructed to complete diaries at approximately the same time each evening and return them the following day. To be included in the final sample, participants had to complete a minimum of 24 interviews and 24 diaries in the 30-day period. The 239 participants were in the study for a total of 7,170 days ( 30 days each). As a result of missing data, 460 days were excluded from analyses. Thus, the reported analyses reflect 6,710 days of data.

As a visual illustration, Figure 3 displays the intra-individual variation in daily affect and daily stress for a participant with a high level of SCD (i.e., low self-concept coherence). Similarly, Figure 4 displays the intra-individual variation in daily affect and daily stress for a participant with a low level of SCD (i.e., high self-concept coherence). Inspection of Figure 3 reveals several noteworthy observations with regard to the affective ratings of the individual with high SCD. First, there is a good deal of covariation between the positive and negative affect ratings. Specifically, negative affect ratings tend to go up when positive affect ratings tend to go down and vice versa. Second, this covariation tends to be related to the number of daily stressors reported by the individual. That is, on days with a larger number of stressful events, positive affect tends to decrease and negative affect tends to increase. Overall, this individual displays a good deal of intra-individual variation in affect and the displayed data tend to be consistent with the hypothesis of greater volatility of behavior in individuals with high SCD.

In contrast, the data displayed in Figure 4 for a participant with a low level of SCD reveal a quite different pattern of intra-individual variation. First, there is no obvious covariation between the participant's positive and negative affect ratings. The two time-related trajectories appear to be independent from each other, with the individual showing a consistently high level of positive affect and a consistently low level of negative affect. Second, this participant also reported a smaller number of stressful events across the 30-day period and only at one point in time (i.e., between days 14 and 16) did the amount of stress trigger a substantial increase in negative affect.

It is important to keep in mind that these two cases are only presented for illustrative purposes. The displayed data, however, are consistent with the hypothesis that individuals with high SCD tend to have a more volatile person-environment fit and that stressful events result in greater intra-individual variation in measures of positive and negative affect. Similarly, examination of the bivariate correlations of the aggregated data showed associations that were consistent with the study hypotheses (see Table 2). ${ }^{3}$

To examine the association between SCD, stress and intra-individual variation in negative affect for the whole sample and in a statistically rigorous way, we performed multilevel analyses (Raudenbush \& Bryk, 2002; Snijders \& Bosker, 1999). At Level 1 (i.e., within-person

\footnotetext{
${ }^{3}$ Because Baird et al. (2006) criticized the use of the SCD index from a methodological point of view, we performed a set of control analyses in which we calculated the corrected indexes suggested by these authors. Overall, the findings from these analyses replicated the findings reported by Baird et al. (2006). Specifically, the correlations with the outcome measures were attenuated, yet statistically significant, for the index that removed the cross-item variance, whereas the correlations for the index that also controlled for the meanlevel variance tended to drop below the level of statistical significance. This pattern, however, varied by age group. In particular, in the group of older adults the correlations of the second index (i.e., the index that corrects for cross-item and mean-level variance) with the average daily negative affect score and the average score of negative self-attributes remained statistically significant $(p<.05)$. Thus, this finding suggests that even corrected indexes of SCD may show significant associations with relevant outcome measures and that these associations may vary by age.
} 
level), we examined the effect of daily stress, whereas at Level 2 (i.e., between-person level) the effects of age and SCD were examined. These analyses yielded significant effects of daily stress, age, and SCD. Specifically, on days when individuals experienced more than average stress, they also experienced significantly more negative affect than on days with average stress. With regard to the effect of age, individuals older than the sample average ( $M$ age $=$ 49.6 years) tended to show lower average levels of daily negative affect compared to individuals younger than the sample average, with age accounting for $7 \%$ of the betweenperson variation in average levels of negative affect. In terms of the effect of SCD, individuals above the sample mean showed significantly higher average levels of daily negative affect than individuals below the sample mean. SCD accounted for $9 \%$ of the between-person variation in average levels of daily negative affect. The interactions between age and stress, SCD and stress, and age and SCD failed to reach the .05 level of statistical significance.

In subsequent models we examined the associations between age and SCD and the total variation in individuals' daily negative affect (expressed as the within-person standard deviation in negative affect over the 30 days). These analyses revealed that, with increasing age, adults tended to show less variation their daily negative affect, $\beta=-.29, t(236)=-4.69$, $p<.001$. In addition, adults with lower levels of SCD tended to show less variation in daily negative affect, $\beta=.20, t(236)=3.20, p<.01$.

Taken together, these analyses provided support for the hypothesis that SCD is associated with intra-individual variation in daily affect. Specifically, stressful events create disturbances in the person-environment fit for all individuals, such that individuals tend to experience greater negative affect on days they experience a greater than average number of stressors. Yet individuals with higher SCD levels also tend to have higher average levels of negative affect and experience greater day-to-day fluctuations in their daily negative affect.

These overall conclusions were also supported by findings from analyses with corrected SCD indexes (Baird et al., 2006). Using the cross-role standard deviation that controls for crossitem variance, the findings were completely replicated, although the effect of the SCD index was somewhat attenuated. Using the corrected standard deviation that also controlled for meanlevel variance, the analyses partially supported the earlier findings. Although the corrected cross-role standard deviation failed to be significantly associated with participants' daily variation in negative affect, individuals with a higher corrected SCD index experienced significantly more variation in negative affect across the total observation period. ${ }^{4}$

\section{Valence of Daily Self-Representations and Intra-Individual Variability in Negative Affect}

Because of the length of the SCD measure, it was not possible to assess SCD on a daily basis. Instead, we assessed the valence of participants' daily self-representations. In particular, participants responded to a checklist of 20 attributes for 30 consecutive days. The checklist consisted of 10 positive attributes (e.g., agreeable, energetic, kind) and 10 negative attributes (e.g., angry, frustrated, insecure) that can be used as self-descriptors. Participants were asked to rate the extent to which they relied on each attribute in the past 24 hours on a scale from 1 (did not rely at all) to 4 (did rely all the time). Each day the attributes were presented in a

\footnotetext{
${ }^{4}$ We also repeated these analyses using the two corrected SCD indexes suggested by Baird et al. (2006). As would be expected, based on Baird and colleagues' work, the findings were completely replicated for the cross-role standard deviation (i.e., controlling for crossitem variance), although the magnitude of the associations of the cross-role standard deviation with the outcome variables was attenuated. A mixed pattern of findings emerged for the corrected standard deviation that also controlled for the mean-level variance. Although the corrected standard deviation was not significantly associated with variation in daily negative affect (i.e., first multilevel analysis), it was, however, significantly associated with the total variation in negative affect across the 30 days (i.e., second multilevel analysis). Specifically, adults with lower (corrected) SCD tended to show less variation in daily negative affect, $\beta=.13, t(236)=2.19, p<.05$. Given these findings, Baird et al.'s (2006) conclusions may require some qualifications and may warrant additional work with age-heterogeneous samples, examining the role of within-person variability from a developmental perspective.
} 
different random order. The 20 attributes were selected from an original list of 60 selfdescriptors (Donahue et al., 1993) by retaining those that were (a) used successfully in past research assessing adults' self-representations (Diehl et al., 2001) and (b) endorsed with relatively high frequency in studies on trait descriptors (Goldberg, 1992; Sheldon, Ryan, Rawsthorne, \& Ilardi, 1997). Participants' ratings were summed to create two subscales: (a) a positive daily self-representations index and (b) a negative daily self-representations index. Higher scores on the subscales indicate that participants relied more on positive/negative selfattributes on a given day. We estimated the internal consistency coefficient on the 5th, 15th, and 25th days of measurement. The resulting internal consistency coefficients for the positive self-attributes subscale were $.86, .86$, and .87 , respectively, and the coefficients for the negative self-attributes subscale were $.64, .69$, and .70 , respectively.

Table 2 shows the correlations among the between-person and aggregated within-person (daily) variables of interest. As can be seen in Table 2, participants' age was positively associated with the mean of daily positive self-attributes and negatively associated with the mean of daily negative self-attributes. That means that with increasing age, individuals tended to rely more on positive self-attributes on a day-to-day basis and less on negative self-attributes. SCD was negatively associated with the mean of daily positive self-attributes and positively associated with the mean of daily negative self-attributes. Thus, participants with higher SCD scores (i.e., lower self-concept coherence) tended to rely less on positive self-attributes and tended to endorse more negative self-attributes on a day-to-day basis. ${ }^{5}$

Multilevel analyses were performed to examine the effect of daily self-representations on the within-person variation in negative affect in response to daily stress. These analyses showed that on days when participants endorsed negative self-attributes more strongly, they also showed significantly higher levels of negative affect. On the other hand, on days when participants endorsed positive self-attributes more strongly, they tended to show significantly lower levels of negative affect. In combination, the extent to which participants endorsed negative and positive self-attributes on a daily basis accounted for $24 \%$ of the within-person variation in negative affect. ${ }^{6}$

The analyses also examined whether the effect of stress on intra-individual variation in negative affect was moderated by the extent to which adults endorsed positive and negative selfattributes on a day-to-day basis. Findings showed that the Stress $\times$ Negative Self-Attributes interaction was statistically significant, whereas the Stress $\times$ Positive Self-Attributes interaction failed to reach the .05 level of statistical significance. Figure 5 depicts this interaction on days when individuals experienced the median number of stressors (i.e., one stressor) as well as on days when they had no stress or experienced two stressful events. The interaction reveals that when participants endorsed negative self-attributes more strongly, daily stressors had a greater impact on their daily negative affect.

To our knowledge, this is the first study that has examined the role of SCD in such a contextspecific manner. Taken as a whole, these analyses suggest that higher than average SCD (i.e., lower than average self-concept coherence) is a risk factor associated with higher average levels of negative affect as well as greater volatility in daily negative affect. In addition, these analyses suggest that higher than average levels of SCD may also be associated with greater vulnerability

\footnotetext{
${ }^{5}$ Using the corrected indexes suggested by Baird et al. (2006), control analyses showed that both the cross-role standard deviation and the corrected cross-role standard deviation showed significant correlations with daily variability in negative and positive self-attributes (expressed as the within-person standard deviation).

${ }^{6}$ It is important to note that these analyses can only speak to the association between daily self-representations and daily affect. To address the question of whether certain daily self-representations may be causal to the experience of certain affective states, lagged analyses need to be conducted. We plan to address the causality issue in a separate manuscript.
} 
to stress through the influence of SCD on daily self-representations, particularly negative selfrepresentations.

\section{CONCLUSION}

Because of their contextualized and dynamic nature, self-representations have appealed to personality and developmental psychologists because of their potential to account for continuity and discontinuity across the adult life span (Brandtstädter \& Greve, 1994; Hooker \& McAdams, 2003; Markus \& Herzog, 1991; Smith \& Freund, 2002). Specifically, the documentation that by early adulthood individuals' global and cognitively undifferentiated self-descriptions have developed into role- and situation-specific self-representations (Harter 1998, 1999), has motivated life span developmental psychologists to examine the ways in which self-representations are associated with adjustment and psychological well-being (Donahue et al., 1993; Diehl et al., 2001). Most attempts to understand the role of selfrepresentations in adulthood have focused on the structural organization of self-knowledge and have related different self-structures to measures of psychological well-being.

Our own research program has focused on SCD, which is defined as the extent to which a person's self-representations are similar or different across different social roles or situations (Block, 1961). Most studies have shown that high levels of SCD (i.e., low levels of self-concept coherence) tend to be associated with poorer adjustment and psychological well-being (Donahue et al., 1993; Diehl et al., 2001; Lutz \& Ross, 2003; McReynolds et al., 2000). Thus, researchers have drawn the conclusion that high levels of SCD tend to be a sign of selffragmentation rather than a sign of social specialization. Our present research extended this work and examined the role of SCD and the valence of daily self-representations in the context of daily stress and negative affect. Findings from this work suggest that different levels of SCD were in a consistent and meaningful way related to the endorsement of positive and negative self-attributes, which, in turn, were significantly related to the level of daily negative affect and intra-individual variation in negative affect. Thus, these results suggest that SCD may exert its effect on adjustment and psychological well-being through specific ways of processing selfrelated information.

It was also reassuring to find that the overall pattern of findings was mostly retained when corrected indexes of SCD were used (Baird et al., 2006). Although our findings were mostly consistent with these authors' results based on samples of college students, the fact that the corrected SCD indexes showed significant associations with some within-person attributes for the older adult age group also suggests that the role of within-person variability in personality constructs such as SCD may not be constant across the whole adult lifespan. Thus, although Baird and his colleagues (2006) have provided important methodological insights with regard to the measurement of SCD, their conclusions may require some further examination with more age-heterogeneous samples and with samples that permit the examination of the extent to which intra-individual variability over relatively short periods of time may be linked to developmental change over longer periods of time.

The issue of the relationship between age and SCD also warrants further investigation because the currently available evidence is too scant and remains inconclusive. On one hand, based on cross-sectional data, the research by Diehl et al. (2001) has shown that SCD and age were associated with each other in a nonlinear fashion, suggesting that SCD may be related to individuals' role-specific experiences and to the developmental demands of specific life stages (see Wood \& Roberts, 2006). On the other hand, data from our daily diary study have shown a linear negative relationship between age and SCD. Although these differences cannot be easily reconciled, the findings from both studies suggest that a more coherent self-concept (i.e., lower SCD) may be of greater importance for adjustment and well-being starting in midlife 
compared to early adulthood. However, to address the core questions of why and how SCD may change with age and what the causes for change in SCD may be, long-term longitudinal studies are needed. We plan to address some of these issues with a first longitudinal followup of our daily diary sample. Because of some initial evidence that the experience of positive and negative life events is differentially related to the temporal stability of self-representations (Diehl, Jacobs, \& Hastings, 2006), we expect that changes in young, middle-aged and older adults' SCD index would be related to changes in their role-specific self-representations. In turn, we expect that changes in individuals' role-specific self-representations will be related to role experiences, life events, and life stage specific developmental tasks. This reasoning is consistent with the Personality and Role Identity Structural Model (PRISM) outlined by Wood and Roberts (2006) and extends this model into the realm of self-representations and structural organizations of adults' self-concept.

Finally, we would like to address the occasionally raised criticism concerning whether the effects of SCD may be explained by some other broader, dispositional personality characteristic such as neuroticism. Critics who present this argument take the stance that SCD may not be a distinct psychological construct but may simply act as a proxy variable for a third variable such as neuroticism or trait anxiety. This argument is, to some extent, consistent with the observation that age and neuroticism are negatively associated — an association that has been well documented in both cross-sectional and longitudinal studies (see Terracciano, McCrae, Brant, $\&$ Costa, 2005). Although this argument has a great deal of plausibility, we have addressed this potential alternative explanation in analyses with our own data. The results of these analyses showed that neuroticism and SCD have independent effects on outcome measures such as daily affect or other markers of subjective well-being. Moreover, our data also showed that the effect of SCD tended to be larger than the effect of neuroticism. Thus, we are reasonably confident that SCD represents a distinct and nonredundant psychological construct that can contribute to elucidating the associations between personality in context and outcomes such as psychological well-being.

\section{Acknowledgements}

The research presented in this article was supported by grants R03 AG19328 and R01 AG21147 from the National Institute on Aging to Manfred Diehl. The authors would like to thank Brent Roberts and an anonymous reviewer for their thoughtful comments on an earlier version of the manuscript.

\section{References}

Almeida DM, Wethington E, Kessler RC. The Daily Inventory of Stressful Experiences (DISE): An interview-based approach for measuring daily stressors. Assessment 2002;9:41-55. [PubMed: 11911234]

Baird BM, Le K, Lucas RE. On the nature of intraindividual personality variability: Reliability, validity, and associations with well-being. Journal of Personality and Social Psychology 2006;90:512-527. [PubMed: 16594835]

Baumeister, RR. The self. In: Gilbert, DT.; Fiske, ST.; Lindzey, G., editors. The handbook of social psychology. 4. 1. New York: McGraw-Hill; 1998. p. 680-740.

Bigler M, Neimeyer GJ, Brown E. The divided self revisited: Effects of self-concept clarity and selfconcept differentiation on psychological adjustment. Journal of Social and Clinical Psychology 2001;20:396-415.

Block J. Ego-identity, role variability, and adjustment. Journal of Consulting and Clinical Psychology 1961;25:392-397.

Brandtstädter J, Greve W. The aging self: Stabilizing and protective processes. Developmental Review 1994;14:52-80.

Campbell JD, Assanand S, DiPaula A. The structure of the self-concept and its relations to psychological adjustment. Journal of Personality 2003;71:115-140. [PubMed: 12597239] 
Campbell JD, Trapnell PD, Heine SJ, Katz IM, Lavallee LF, Lehman DR. Self-concept clarity: Measurement, personality correlates, and cultural boundaries. Journal of Personality and Social Psychology 1996;70:141-156.

Caspi A, Roberts BW. Personality development across the life course: The argument for change and continuity. Psychological Inquiry 2001;12:49-66.

Cross S, Markus H. Possible selves across the life span. Human Development 1991;34:230-255.

Damon, W.; Hart, D. Self-understanding in childhood and adolescence. New York: Cambridge University Press; 1988.

Diehl, M. Self-concept organization across the adult life span. University of Florida; 2001. Unpublished grant application

Diehl, M. Development of self-representations in adulthood. In: Mroczek, DK.; Little, TD., editors. Handbook of personality development. Mahwah, NJ: Erlbaum; 2006. p. 373-398.

Diehl M, Hastings CT, Stanton JM. Self-concept differentiation across the adult life span. Psychology and Aging 2001;16:643-654. [PubMed: 11766918]

Diehl M, Hay EL, Aertker L. Examining the combined effect of self-concept differentiation and selfconcept clarity on adults' psychological well-being. 2006Manuscript submitted for publication

Diehl M, Jacobs LM, Hastings CT. Temporal stability and authenticity of self-representations in adulthood. Journal of Adult Development 2006;13:10-22.

Donahue EM, Robins RW, Roberts BW, John OP. The divided self: Concurrent and longitudinal effects of psychological adjustment and social roles on self-concept differentiation. Journal of Personality and Social Psychology 1993;64:834-846. [PubMed: 8505712]

Erikson, EH. Childhood and society. 2. New York: Norton; 1963.

Filipp, S-H.; Klauer, T. Conceptions of self over the life span: Reflections on the dialectics of change. In: Baltes, MM.; Baltes, PB., editors. The psychology of control and aging. Hillsdale, NJ: Erlbaum; 1986. p. 167-205.

Freund AM, Smith J. Content and function of the self-definition in old and very old age. Journal of Gerontology: Psychological Sciences 1999;54B:P55-P67.

Gergen, KJ. The saturated self: Dilemmas of identity in contemporary life. New York: Basic Books; 1991.

Goldberg LR. The development of markers for the Big-Five factor structure. Psychological Assessment 1992;4:26-42.

Greve W, Wentura D. Immunizing the self: Self-concept stabilization through reality-adaptive selfdefinitions. Personality and Social Psychology Bulletin 2003;29:39-50. [PubMed: 15272958]

Harter, S. The development of self-representations. In: Damon, W.; Eisenberg, N., editors. Handbook of child psychology: Vol. 3. Social, emotional, and personality development. 5. New York: Wiley; 1998. p. 553-617.

Harter, S. The construction of the self: A developmental perspective. New York: Guilford; 1999.

Harter S, Monsour A. Developmental analysis of conflict caused by opposing attributes in the adolescent self-portrait. Developmental Psychology 1992;28:251-260.

Helson R, Wink P. Personality change in women from the early 40s to the early 50s. Psychology and Aging 1992;7:46-55. [PubMed: 1558705]

Higgins ET. The "self digest": Self-knowledge serving self-regulatory functions. Journal of Personality and Social Psychology 1996;71:1062-1083. [PubMed: 8979379]

Hooker, K. Possible selves in adulthood: Incorporating teleonomic relevance into studies of the self. In: Hess, T.; Blanchard-Fields, F., editors. Social cognition and aging. San Diego, CA: Academic Press; 1999. p. 97-121.

Hooker K, McAdams DP. Personality reconsidered: A new agenda for aging research. Journal of Gerontology: Psychological Sciences 2003;58B:P296-P304.

Kling KC, Ryff CD, Essex MJ. Adaptive changes in the self-concept during a life transition. Personality and Social Psychology Bulletin 1997;23:981-990.

Koch EJ, Shepperd JA. Is self-complexity linked to better coping? A review of the literature. Journal of Personality 2004;72:727-760. [PubMed: 15210015]

Lachman ME. Development in midlife. Annual Review of Psychology 2004;55:305-331. 
Lecky, P. Self-consistency: A theory of personality. New York: Anchor Books; 1945.

Linville PW. Self-complexity and affective extremity: Don't pull all your eggs in one cognitive basket. Social Cognition 1985;3:94-120.

Linville PW. Self-complexity as a cognitive buffer against stress-related illness and depression. Journal of Personality and Social Psychology 1987;52:663-676. [PubMed: 3572732]

Locke KD. What predicts well-being: A consistent self-concept or a desirable self-concept? Journal of Social and Clinical Psychology 2006;25:228-247.

Lutz CJ, Ross SR. Elaboration versus fragmentation: Distinguishing between self-complexity and selfconcept differentiation. Journal of Social and Clinical Psychology 2003;22:537-559.

Marcia, JE. Identity in adolescence. In: Adelson, J., editor. Handbook of adolescent psychology. New York: Wiley; 1980. p. 159-187.

Margolin JB, Niedenthal PM. Manipulating self-complexity with communication role assignment: Evidence for the flexibility of self-concept structure. Journal of Research in Personality 2000;34:424444.

Markus, HR.; Herzog, RA. The role of the self-concept in aging. In: Schaie, KW., editor. Annual review of gerontology and geriatrics. 11. New York: Springer; 1991. p. 110-143.

Markus HR, Kunda Z. Stability and malleability of the self-concept. Journal of Personality and Social Psychology 1986;51:858-866. [PubMed: 3783430]

Markus HR, Wurf E. The dynamic self-concept: A social psychological perspective. Annual Review of Psychology 1987;38:299-337.

McReynolds P, Altrocchi J, House C. Self-pluralism: Assessment and relations to adjustment, life changes, and age. Journal of Personality 2000;68:347-381. [PubMed: 10820690]

Montemayor R, Eisen M. The development of self-conceptions from childhood to adolescence. Developmental Psychology 1977;13:314-319.

Mroczek, DK.; Spiro, A.; Griffin, PW. Personality and aging. In: Birren, JE.; Schaie, KW., editors. Handbook of the psychology of aging. 6. San Diego, CA: Academic Press; 2006. p. 363-377.

Rafaeli-Mor E, Steinberg J. Self-complexity and well-being: A review and research synthesis. Personality and Social Psychology Review 2002;6:31-58.

Raudenbush, SW.; Bryk, AS. Hierarchical linear models: Applications and data analysis methods. 2. Thousand Oaks, CA: Sage; 2002.

Rogers, C. A theory of therapy, personality, and interpersonal relationships, as developed in the clientcentered framework. In: Koch, S., editor. Psychology: A study of science: Vol. 3. Formulations of the person and the social Formulations of the person and the social context. New York: McGrawHill; 1959. p. 184-256.

Rosenberg, M. Self-concept from middle childhood through adolescence. In: Suls, J.; Greenwald, AG., editors. Psychological perspectives on the self. 3. Hillsdale, NJ: Erlbaum; 1986. p. 182-205.

Rothermund K, Meiniger C. Stress-buffering effects of self-complexity: Reduced affective spillover or self-regulatory processes? Self and Identity 2004;3:263-281.

Ryff, CD.; Kwan, CML.; Singer, BH. Personality and aging: Flourishing agendas and future challenges. In: Birren, JE.; Schaie, KW., editors. Handbook of the psychology of aging. 5. San Diego, CA: Academic Press; 2001. p. 477-499.

Sheldon KM, Ryan RM, Rawsthorne LJ, Ilardi B. Trait self and true self: Cross-role variation in the Big Five personality traits and its relations with psychological authenticity and subjective well-being. Journal of Personality and Social Psychology 1997;73:1380-1393.

Showers CJ. Compartmentalization of positive and negative self-knowledge: Keeping bad apples out of the bunch. Journal of Personality and Social Psychology 1992a;62:1036-1049. [PubMed: 1619548]

Showers CJ. Evaluatively integrative thinking about characteristics of the self. Personality and Social Psychology Bulletin 1992b;18:719-729.

Showers CJ, Abramson LY, Hogan ME. The dynamic self: How the content and structure of the selfconcept change with mood. Journal of Personality and Social Psychology 1998;75:478-493. [PubMed: 9731320]

Showers CJ, Kling KC. Organization of self-knowledge: Implications for recovery from sad mood. Journal of Personality and Social Psychology 1996;70:578-590. [PubMed: 8851742] 
Showers, CJ.; Zeigler-Hill, V. Organization of self-knowledge: Features, functions, and flexibility. In: Leary, MR.; Tangney, JP., editors. Handbook of self and identity. New York: Guilford; 2003. p. 47-67.

Smith J, Freund AM. The dynamics of possible selves in old age. Journal of Gerontology: Psychological Sciences 2002;57B:P492-P500.

Snijders, TAB.; Bosker, RJ. Multilevel analyses: An introduction to basic and advanced multilevel modeling. London: Sage; 1999.

Snyder M. Self-monitoring of expressive behavior. Journal of Personality and Social Psychology 1974;30:526-537.

Terracciano A, McCrae RR, Brant LJ, Costa PT Jr. Hierarchical linear modeling analyses of the NEOPI-R scales in the Baltimore Longitudinal Study of Aging. Psychology and Aging 2005;20:493-506. [PubMed: 16248708]

Waterman, AS.; Archer, SL. A life-span perspective on identity formation: Developments in form, function, and process. In: Baltes, PB.; Featherman, DL.; Lerner, RM., editors. Life-span development and behavior. 10. Hillsdale, NJ: Erlbaum; 1990. p. 29-57.

Wood D, Roberts B. Cross-sectional and longitudinal tests of the personality and role identity structural model (PRISM). Journal of Personality 2006;74:779-809. [PubMed: 16684253]

Woolfolk RL, Novalany J, Gara MA, Allen LA, Polino M. Self-complexity, self-evaluation, and depression: An examination of form and content within the self-schema. Journal of Personality and Social Psychology 1995;68:1108-1120. [PubMed: 7608857] 


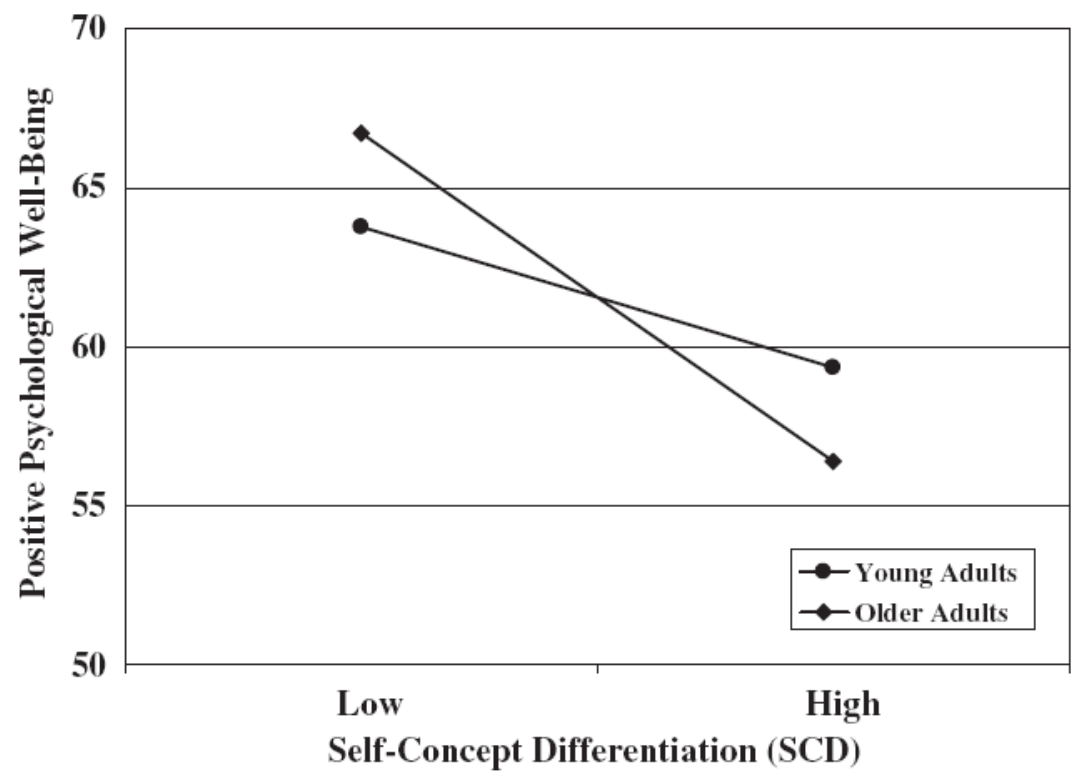

Figure 1.

Interaction of self-concept differentiation and age for positive psychological well-being (Diehl et al., 2001; reprinted with permission). 


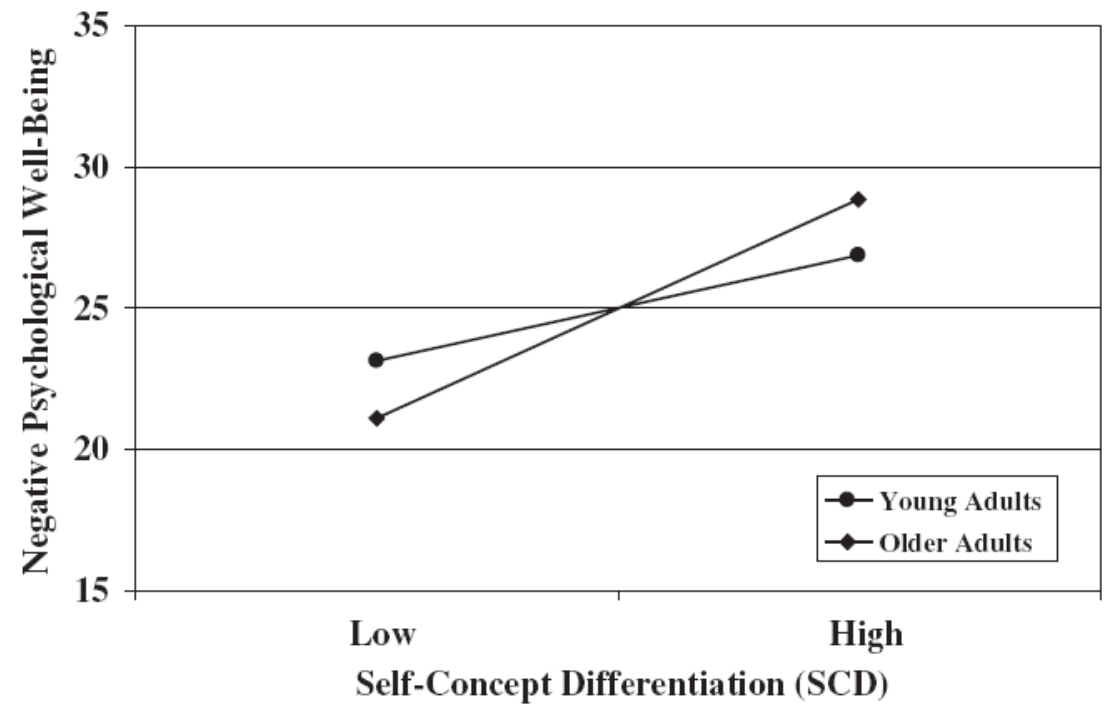

Figure 2.

Interaction of self-concept differentiation and age for negative psychological well-being (Diehl et al., 2001; reprinted with permission). 


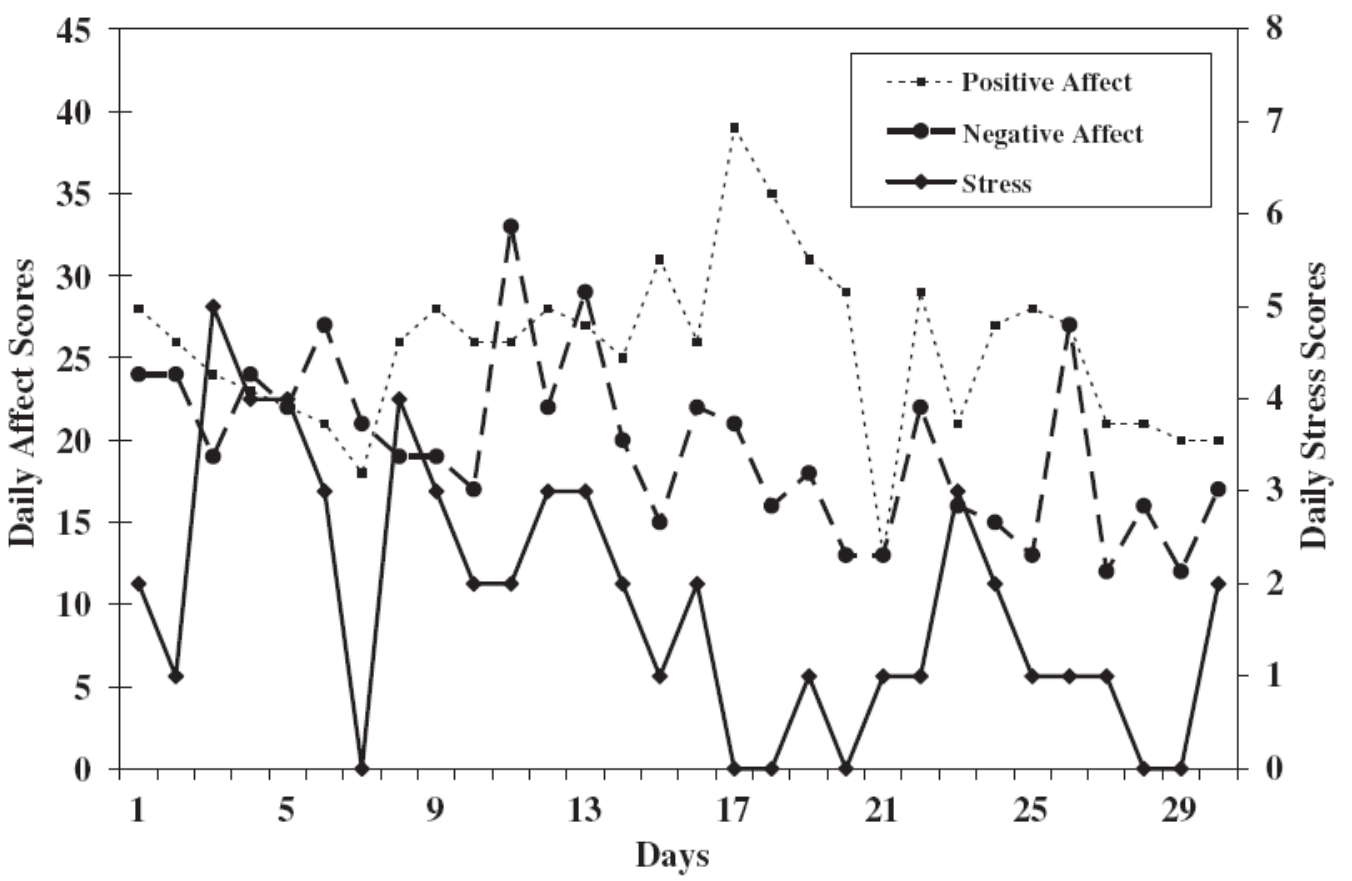

Figure 3.

Intraindividual variability in positive and negative affect for a participant with high SCD (i.e., low self-concept coherence). 


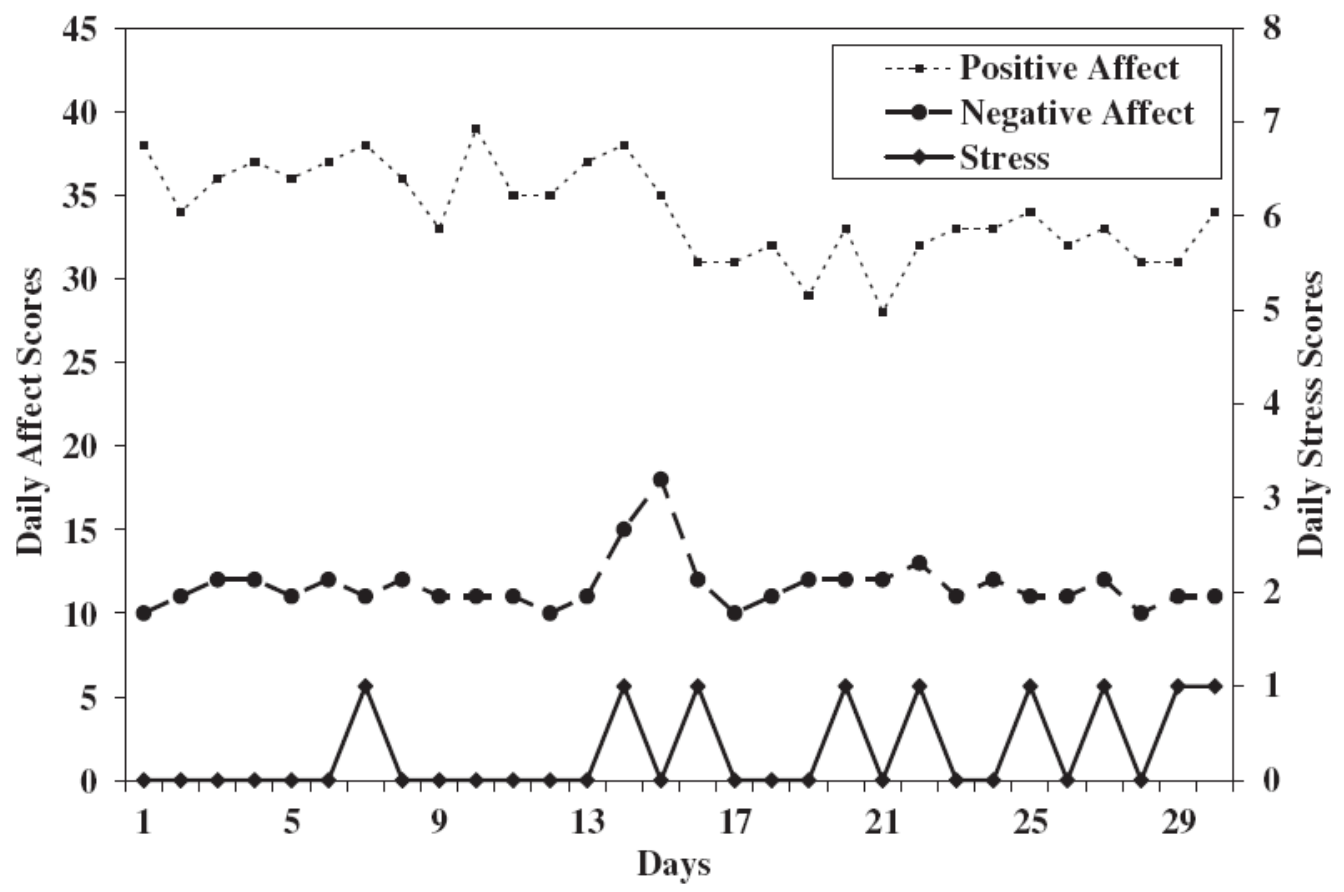

Figure 4.

Intraindividual variability in positive and negative affect for a participant with low SCD (i.e., high self-concept coherence). 


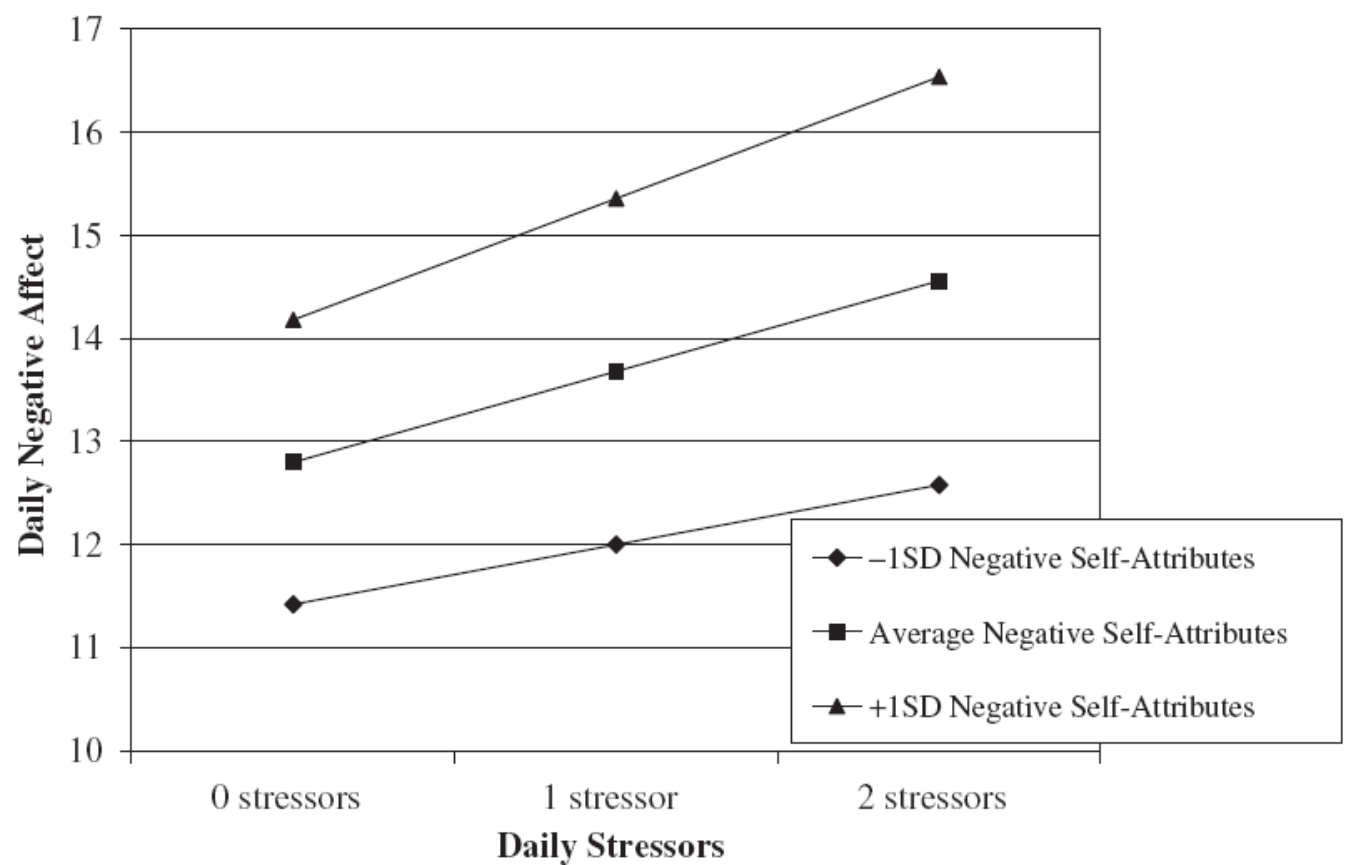

Figure 5.

Interaction of daily stressors and daily negative self-attributes for daily negative affect. 


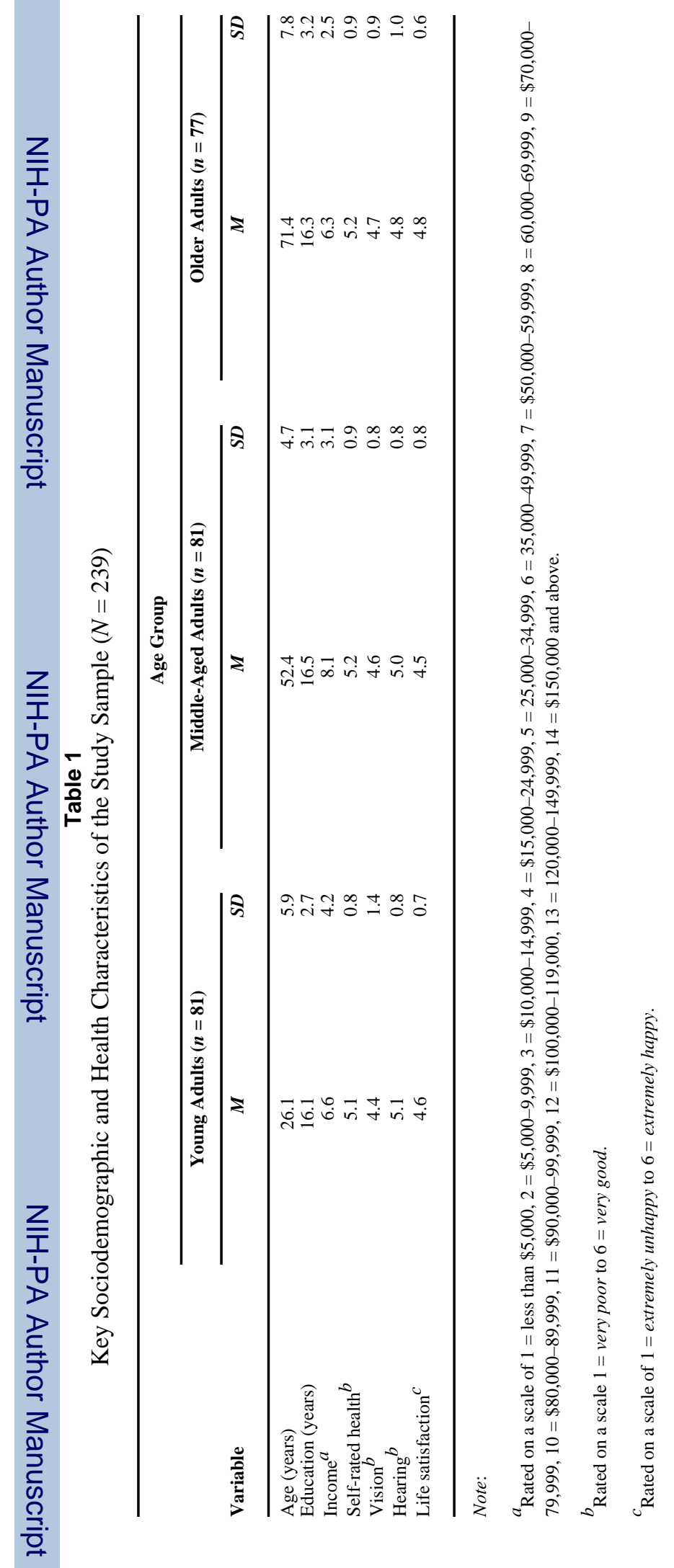




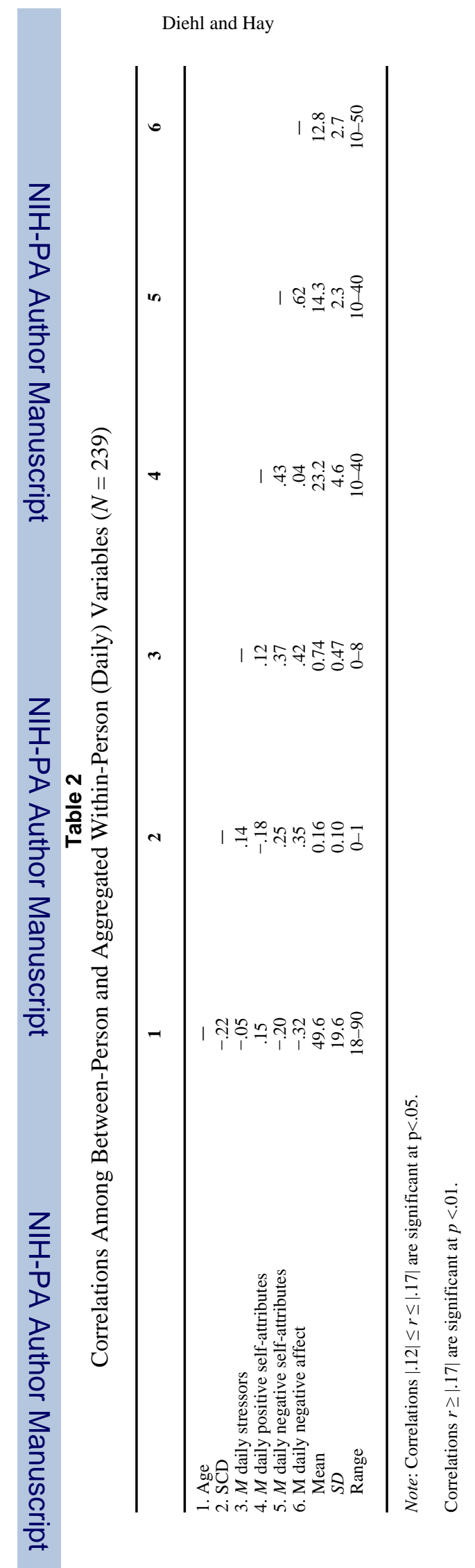

J Pers. Author manuscript; available in PMC 2008 June 20. 